\title{
PRODUTIVIDADE E ACÚMULO DE ENXOFRE (S) EM CEBOLA CULTIVADA EM SOLO CAMBISSOLO HÁPLICO
}

\author{
Robinson Jardel Pires de Oliveira ${ }^{1}$, Marlon Goede ${ }^{1}$, Romano Roberto Valicheski ${ }^{2}$, Leandro Luiz \\ $\operatorname{Marcuzzo}^{1 *}$, Rérinton Pires Oliveira ${ }^{3}$ \\ ${ }^{1}$ Instituto Federal Catarinense - Campus Rio do Sul, Rio do Sul, 89163-356, Santa Catarina, Brasil \\ ${ }^{2}$ Instituto Federal Goiano - Campus Iporá, Iporá, 76200-000, Goiás, Brasil \\ ${ }^{3}$ Embrapa Clima Temperado, Pelotas, 96010-971, Rio Grande do Sul, Brasil
}

*Autor para correspondência: Robinson Jardel Pires de Oliveira; e-mail: robinson.oliveira@ifc.edu.br

Recebido: 03/06/2020, Aceito: 19/05/2021

\begin{abstract}
Resumo
O presente trabalho foi implantado na área experimental do Instituto Federal Catarinense (IFC - Campus Rio do Sul), permanecendo no campo por 150 dias e utilizou-se a cultivar de cebola bola precoce, tradicionalmente cultivada na região do Alto Vale do Itajaí (SC). O objetivo foi avaliar a resposta da cultura da cebola a diferentes doses de S, sendo o delineamento em blocos casualizados, com cinco tratamentos $\left(0,30,60,90\right.$ e $120 \mathrm{~kg} \mathrm{ha}^{-1} \mathrm{de}$ $\mathrm{S})$, e quatro repetições em parcelas com $2,66 \mathrm{~m}^{2}$. O espaçamento entre linhas de $0,33 \mathrm{~m}$ e entre plantas de $0,10 \mathrm{~m}$, com 20 plantas por linhas e 80 plantas por parcela, sendo colhidas 10 plantas centrais para as análises. Foi determinando o diâmetro de bulbo, número de bainhas laminares e matéria fresca e seca de folhas e bulbos. Para a análise de enxofre no solo, as amostras de solo foram coletadas na profundidade de $0,0-0,20 \mathrm{~m}$ em todas as parcelas. Após secas em estufa, as amostras foram moídas e passadas em peneira com malha de $2 \mathrm{~mm}$. As amostras de tecido (folha e bulbo) e solo foram abertas por digestão nitroperclórica, seguido de leitura em espectrofotocolorímetro no comprimento de onda de $440 \mathrm{~nm}$. Todos os dados foram submetidos à análise de variância com aplicação do Teste $F$ a $1 \%$ e 5,0\% de probabilidade de erro. A adubação com $30 \mathrm{~kg} \mathrm{ha}^{-1}$ de S teve influência sobre a produtividade da cebola. A adição de $30 \mathrm{~kg} \mathrm{ha}^{-1}$ de $\mathrm{S}$ no solo apresentou maior acúmulo de $\mathrm{S}$ no tecido.
\end{abstract}

Palavras-chave: Allium cepa, nutrição de plantas, adubação sulfatada

\section{PRODUCTIVITY AND ACCUMULATION OF SULFUR (S) IN ONION CULTIVATED IN HAPLIC CAMBISSOLO SOIL}

\begin{abstract}
The present study was implemented in the experimental area of the Instituto Federal Catarinense (IFC - Campus Rio do Sul), remaining in the field for 150 using the anion "ball" early cultivar, which traditionally grows in the Alto Vale do Itajaí (SC) region, Brazil. The objective was to evaluate the response of the onion culture to different doses of $\mathrm{S}$, with a randomized complete block design with five treatments $\left(0,30,60,90\right.$, and $120 \mathrm{~kg} \mathrm{ha}^{-1}$ of $\left.\mathrm{S}\right)$, and four replications in plots with 2,66 $\mathrm{m}^{2}$. The line spacing of $0.33 \mathrm{~m}$ and between $0.10 \mathrm{~m}$ plants, with 20 plants per line and 80 plants per plot, 10 central plants were collected for analysis. It was determined the bulb diameter, number of leaf sheaths, and fresh and dry mass of leaves and bulbs. For soil sulfur analysis, soil samples were collected at depths of 0.0-0.20 m in all plots. After oven drying, the samples were milled and sieved with a $2 \mathrm{~mm}$ mesh. The tissue (leaf and bulb) and soil samples were opened by nitroperchloric digestion, followed by and spectrophotometer reading at the wavelength of $440 \mathrm{~nm}$. All data were submitted to analysis of variance with the application of the $1 \% \mathrm{~F}$ test and $5.0 \%$ probability of error, whereas differences between treatments were assessed by the Skott-Knott test, using the SASm program. The fertilization with $30 \mathrm{~kg} \mathrm{ha}^{-1}$ of S had an influence on the productivity of the onion culture. The addition of $30 \mathrm{~kg} \mathrm{ha}^{-1}$ of $S$ in the soil showed a greater accumulation of $S$ in the tissue.
\end{abstract}

Keywords: Allium cepa, plant nutrition, sulphated ferilization 


\section{Introdução}

Dentre as várias espécies pertencentes ao gênero Allium, a cebola é a mais importante tanto pelo volume de produção quanto pela parte econômica (RESENDE et al, 2007). Segundo dados do Instituto Brasileiro de Geografia e Estatística (IBGE, 2019), no Brasil foram cultivados 48.683 ha de cebola na safra 2019, atingindo uma produção total 1.556 .885 toneladas, com rendimento médio de $32.337 \mathrm{Kg} \mathrm{ha}^{-1}$. O estado de Santa Catarina é o principal produtor de cebola no Brasil, com cerca de $29 \%$ da produção nacional, produzindo em 2019 de 457.221 toneladas e uma produtividade média de $26.618 \mathrm{Kg} \mathrm{ha}^{-1}$ (IBGE, 2019). O cultivo da cebola para na região Sul se destaca nos aspectos sociais e econômicos, podendo ser avaliada pela significativa geração de emprego e renda e, consequente fixação do agricultor no meio rural por ser uma atividade predominantemente em regime familiar (KURTZ et al., 2013).

O enxofre (S) é o quarto macronutriente mais aplicado na nutrição das plantas e está relacionado à produção de matéria verde, pois é constituinte de proteínas, aminoácidos essenciais, membranas celulares e outros compostos, além de possuir função no transporte de elétrons (TAIZ \& ZEIGER, 2006; MALAVOLTA et al., 1997) sendo indiscutível a sua essencialidade às plantas (THOMAS et al., 1950), principalmente em espécies que apresentam alta demanda deste nutriente, tais como a cebola, o alho e a beterraba (KLIKOCKA, 2010).

Dentre os fatores que limitam a disponibilidade do $\mathrm{S}$ nas plantas, podem ser citados os solos com baixos teores de argila, baixos teores de óxidos e baixos teores de matéria orgânica. Aliado a isso, a realização da calagem e da adubação com fosfatos solúveis na camada superficial facilita a migração do SO4-2 às camadas subsuperficiais, que por limitações físicas e químicas podem não ser acessadas pelo sistema radicular (RHENHEIMER et al., 2005).

Vários autores tem relatado a deficiência de $\mathrm{S}$ em diversas partes do mundo, dentre eles SCHERER, (2001), AULAKH, (2003) e JAGGI et al., (2005), os quais descrevem que a utilização de fertilizantes sulfatados tem aumentado a produção e a qualidade das raízes produzidas. Dentre os fertilizantes que contém $\mathrm{S}$, o enxofre elementar $\mathrm{S}\left(\mathrm{S}^{\circ}\right)$ está se tornando cada vez mais popular, pois contribui reduzindo a lixiviação e as perdas por escoamento, deixando efeitos residuais prolongados, favorecendo assim os cultivos subsequentes. Porém, estudos com este elemento para olericultura ainda são escassos no país.

$\mathrm{Na}$ região do Alto Vale do Itajaí (SC) frequentemente é feita a adição excessiva de fertilizantes, principalmente contendo NPK, bem como o uso de corretivos de acidez sem critérios técnicos adequados, porém o $\mathrm{S}$ é o macronutriente menos empregado diretamente nas adubações (KURTZ \& ERNANI, 2010). Segundo CQFS-RS/SC, (2004), dada sua importância na olericultura, este elemento deve ser monitorado, uma vez que formulações concentradas de NPK, geralmente com baixo teor de enxofre, poderão não suprir adequadamente esse nutriente nas hortaliças, sendo recomendado o uso de formulações que contenham enxofre, bem como o monitoramento pela análise de solo.

Diante da carência de pesquisas sobre aspectos da nutrição sulfatada para a cultura da cebola, o presente trabalho objetivou avaliar o efeito do enxofre (S) sobre o desenvolvimento e produção da cebola na região do Alto Vale do Itajaí, procurando assim estabelecer uma recomendação para este nutriente na principal classe de solo.

\section{Material e Métodos}

O presente trabalho foi implantado na área experimental do IFC - Campus Rio do Sul, no dia 29 de junho de 2016, permanecendo no campo por 150 dias e utilizou-se a cultivar bola precoce, tradicionalmente cultivada na região do Alto Vale do Itajaí. As mudas foram obtidas de viveiro de mudas, obedecendo às orientações técnicas e agronômicas para a produção das mudas, e após atingirem o seu tamanho e porte foram levadas ao campo experimental.

$\mathrm{O}$ solo da área experimental é um Cambissolo háplico, com os seguintes atributos químicos: $\mathrm{pH}$ em água de 5,5; M.O. $(4,3)$, teores de $\mathrm{Ca}^{+2}(6,8)$, de $\mathrm{Mg}^{+2}$ $(3,1), \mathrm{Al}^{+3}(0,00)$ e CTC $(15,0)$, em cmolc $\mathrm{dm}^{3}$; saturação por bases de $68.69 \%$, teor de argila de $19,0 \%$ e teores de S $(14,4), \mathrm{P}(8,7)$ e $\mathrm{K}^{+}(158,0)$, em $\mathrm{mg} \mathrm{dm}{ }^{3}$. Conforme recomendação para a cultura, realizou-se a aplicação de calcário (para elevar o pH do solo a 6,0) 70 dias antes da semeadura.

O delineamento experimental utilizado foi blocos casualizado, com cinco tratamentos correspondendo nas doses de enxofre no solo $\left(0,30,60,90\right.$ e $120 \mathrm{~kg} \mathrm{ha}^{-1} \mathrm{de}$ $\mathrm{S})$, com quatro repetições, totalizando 20 parcelas. $\mathrm{O}$ experimento foi conduzido em parcelas com 2,66 $\mathrm{m}^{2}$. Em cada parcela, o espaçamento entre linhas foi de 0,33 $\mathrm{m}$, e entre plantas de $0,10 \mathrm{~m}$ num total de quatro linhas, compostas por 20 plantas cada linha, totalizando 80 plantas por parcela.

Foram determinados o diâmetro de bulbo (DB) com o auxílio do paquímetro, número de bainhas laminares (NBL; contagem numérica) e matéria fresca de folhas (MFF) e bulbos (MFB) com o auxílio de uma balança de precisão (duas casas decimais). Em seguida, todo o material coletado foi submetido a secagem em estufa $\left(60{ }^{\circ} \mathrm{C}\right.$ até estabilização do peso), determinando-se em 
balança de precisão a matéria seca de bulbo e folhas (MTS)

Os teores de $\mathrm{S}$ no tecido e no solo foram determinados na biomatéria e no solo após digestão nitroperclórica seguindo a metologia descrita por Tedesco et al. (1995); sendo que após a digestão, determinou-se o teor de $\mathrm{S}$ no tecido e no solo por turbidimetria, utilizando-se um espectrofotocolorímetro no comprimento de onda de $440 \mathrm{~nm}$. Para a análise de enxofre no solo, as amostras de solo foram coletadas na profundidade de $0,0-0,20 \mathrm{~m}$ em todas as parcelas. Após secas em estufa, moídas e passadas em peneira com malha de $2 \mathrm{~mm}$, foi determinado $\mathrm{S}_{-} \mathrm{SO}_{4}{ }^{-2}$ disponível pelo extrator $\mathrm{Ca}\left(\mathrm{H}_{2} \mathrm{PO}_{5}\right)^{2}$.

Após tabulação, todos os dados foram submetidos à análise de variância com aplicação do Teste $F$ a 5,0\% de probabilidade de erro, utilizando-se o programa SASm Agri (CANTERI et al., 2001). As diferenças entre os tratamentos foram avaliados pelos modelos de regressão linear ou polinomial de $2^{\mathrm{a}}$ ordem.

\section{Resultados e Discussão}

Para as variáveis biométricas matéria fresca de bulbo (MFB), matéria total fresca $(\mathrm{MTF}=$ bulbo + folha $)$ e diâmetro de bulbo (DB) houve efeito significativo para a aplicação de enxofre no solo (TABELA 1). Esta resposta da cebola à aplicação deste elemento está associada ao papel funcional do $\mathrm{S}$ na produção de proteínas e clorofila, sendo também componente de alguns hormônios da planta, melhorando o crescimento das raízes e aumentando a produtividade (MENDONÇA \& PEIXOTO, 1991). Para matéria seca de bulbo (MSB), matéria fresca de folha (MFF), matéria seca de folha (MSF), matéria total seca (MTS= bulbo + folha) e número de bainhas laminares (NBL), não houve resposta a aplicação de enxofre no solo (TABELA 1). Para efeito de bloco, também não houve efeito significativo, indicando que o solo da área é uniforme, não sendo necessário a aplicação deste delineamento experimental.

A adubação com enxofre teve influência sobre a matéria fresca, matéria total fresca e diâmetro de bulbos, sendo que o tratamento com $30 \mathrm{~kg} \mathrm{ha}^{-1}$ de $\mathrm{S}$ superior ao tratamento testemunha $\left(0 \mathrm{~kg} \mathrm{ha}^{-1}\right.$ de $\left.\mathrm{S}\right)$ e o tratamento com (120 kg ha-1 de $S$ ), por sua vez não diferindo dos tratamentos com (60 e $90 \mathrm{~kg} \mathrm{ha}^{-1}$ de S) (TABELA 1) e ajustados a equação polinomial de segundo grau com $\mathrm{R}^{2}$ de 0,$96 ; 0,91$ e 0,98 respectivamente em cada variável (FIGURA 1). No tratamento com $30 \mathrm{~kg} \mathrm{ha}^{-1} \mathrm{de} \mathrm{S}$ foram produzidas $47,18 \mathrm{t} \mathrm{ha}^{-1}$ de cebola, produção superior à média catarinense que é de 26,61 t ha ${ }^{-1}$ (IBGE, 2019). A dose $30 \mathrm{~kg} \mathrm{ha}^{-1}$ de $\mathrm{S}$ está dentro das recomendações típicas de $\mathrm{S}$, que variam de 20 a $40 \mathrm{~kg} \mathrm{ha}^{-1}$, como sugerido por Vitti et al. (1988).

TABELA 1. Valores de $F$ e nível de significância para as diversas fontes de variação e coeficiente de variação para as variáveis biométricas avaliadas. Rio do Sul, IFC/Campus Rio do Sul, 2016

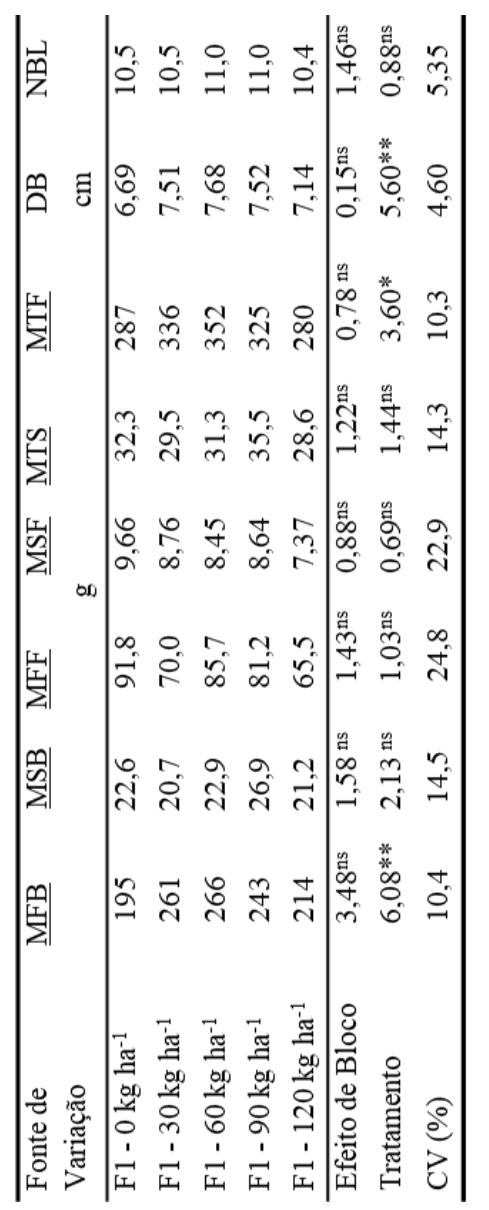

F1=fator $1-$ dose de S; ** Significativo ao nível de 1\% de probabilidade; * Significativo ao nível de $5 \%$ de probabilidade, ${ }^{\text {ns= }}$ Não significativo ao nível de 5\% de probabilidade. Legenda: $\mathrm{CV}=$ coeficiente de variação; MSB = matéria seca de bulbo; MSF =matéria seca de folha; MFB = matéria fresca de bulbo; $\mathrm{MFF}=$ matéria fresca de folha; MTS = matéria total seca; $\mathrm{MTF}=$ matéria total fresca; $\mathrm{DB}=$ diâmetro de bulbo; NBL=número de bainha laminar.

Para a variável acúmulo de enxofre em folhas e bulbos de cebola e teor de enxofre no solo, houve efeito significativo $(P<0,01)$ para a aplicação de enxofre no solo (TABELA 2). Esta resposta da cebola à aplicação de $\mathrm{S}$ está associada ao papel funcional deste elemento na produção de proteínas e clorofila, sendo também componente de alguns hormônios da planta, melhorando o crescimento das folhas e bulbos estimulando a absorção e acúmulo de $\mathrm{S}$ nos tecidos (MENDONÇA \& PEIXOTO, 1991). 


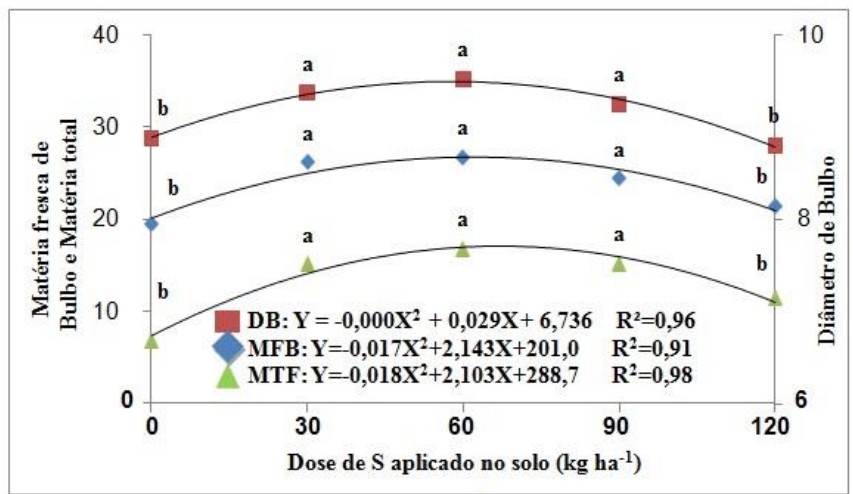

FIGURA 1. Matéria fresca de bulbo (MFB) (g) (símbolos em azul), matéria total fresca (MFT) (g) (símbolos em verde) e diâmetro de bulbo (DB) (cm) (símbolos em vermelho) em função da dose de $\mathrm{S}^{\mathrm{o}}\left(\mathrm{kg} \mathrm{ha}^{-1}\right)$ aplicados no solo. IFC/Campus Rio do Sul, 2016. Letras iguais não diferem pelo teste $F$ ao nível de $5 \%$.

TABELA 2. Valores de F e nível de significância para as fontes de variação relacionadas ao acúmulo de $\mathrm{S}$ em tecidos e teor de enxofre no solo; e coeficiente de variação em função das diversas doses de enxofre aplicadas. IFC/Campus Rio do Sul, 2016

\begin{tabular}{lccc}
\hline & \multicolumn{3}{c}{ Acúmulo de S em tecido e teor de S no solo } \\
\hline F.V. & Folha $\left(\mathrm{kg} \mathrm{ha}^{-1}\right)$ & Bulbo $\left(\mathrm{kg} \mathrm{ha}^{-1}\right)$ & Teor de S no solo $\left(\mathrm{mg} \mathrm{dcm}^{-3}\right)$ \\
\hline $0 \mathrm{~kg} \mathrm{ha}^{-1}$ de S & 3,57 & 12,7 & 14,3 \\
$30 \mathrm{~kg} \mathrm{ha}^{-1}$ de S & 5,93 & 17,4 & 17,6 \\
$60 \mathrm{~kg} \mathrm{ha}^{-1}$ de S & 6,25 & 18,7 & 21,0 \\
$90 \mathrm{~kg} \mathrm{ha}^{-1}$ de S & 6,36 & 18,7 & 25,7 \\
$120 \mathrm{~kg} \mathrm{ha}^{-1}$ de S & 5,81 & 17,8 & 27,9 \\
\hline Bloco & $1,26^{\text {ns }}$ & $0,37^{\text {ns }}$ & $1,566^{\text {ns }}$ \\
Tratamento & $6,19^{* * *}$ & $11,5^{* * *}$ & $24,3^{* *}$ \\
CV $(\%)^{2}$ & 16,5 & 8,51 & 10,6 \\
\hline
\end{tabular}

F.V.= fonte de variação; $C V=$ coeficiente de variação; ** Significativo ao nível de $1 \%$ de probabilidade; ns Não significativo ao nível de $5 \%$ de probabilidade.

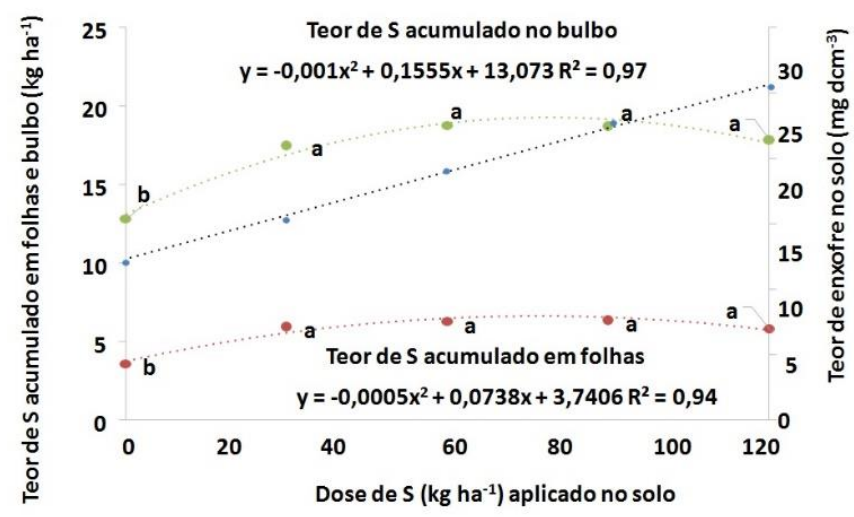

FIGURA 2. Acúmulo de enxofre em folhas (símbolos em vermelho) e bulbos (símbolos em verde) de cebola $\left(\mathrm{kg} \mathrm{ha}^{-1}\right)$ e teor de enxofre no solo $\left(\mathrm{mg} \mathrm{dcm}^{-3}\right)$ (símbolos em azul) em função da dose de $\mathrm{S}^{0}\left(\mathrm{~kg} \mathrm{ha}^{-1}\right)$ aplicados no solo. Letras iguais não diferem pelo teste $F$ ao nível de $5 \%$.

Na Figura 2, observamos um comportamento linear para o teor de $\mathrm{S}$ no solo em função das doses de enxofre aplicadas no solo, sendo $17,66 \mathrm{mg} \mathrm{dm}^{-3}$ o teor considerado ideal para o cultivo da cebola. Já para o acúmulo de $\mathrm{S}$ no tecido em função das doses de enxofre aplicados no solo, observa-se que o modelo modelo polinomial de segunda ordem, foi o mais adequado, obtendo-se $\mathrm{R}^{2}$ de 0,94 e 0,97 para folhas e bulbos, sendo a melhor resposta obtida com a dose $30 \mathrm{~kg} \mathrm{ha}^{-1}$ de S, proporcionando um acúmulo de $\mathrm{S}$ nas folhas de $5,93 \mathrm{~kg}$ $\mathrm{ha}^{-1}$ e em bulbos de $17,47 \mathrm{~kg} \mathrm{ha}^{-1}$, totalizando um acúmulo de $23,40 \mathrm{~kg} \mathrm{ha}^{-1}$ de $\mathrm{S}$ na planta, valor próximo aos obtidos por PORTO et al., (2007), que relataram um acúmulo de $25 \mathrm{~kg} \mathrm{ha}^{-1}$ de $\mathrm{S}$ em tecido de cebola. $\mathrm{O}$ acúmulo de $\mathrm{S}$ foi maior nos bulbos $(74,65 \%)$, enquanto que nas folhas foi de $25,34 \%$. Esse resultado está de acordo com os obtidos por NASREEN et al. (2003), os quais verificaram que o enxofre acumulou-se mais no bulbo, ao final do ciclo da cultura.

\section{Conclusão}

Com $30 \mathrm{~kg} \mathrm{ha}^{-1}$ de $\mathrm{S}$ no solo obteve-se uma produção de 47,18 ton ha ${ }^{-1}$ de cebola e a adição de 30 $\mathrm{kg} \mathrm{ha}^{-1}$ de S no solo apresentou melhor resposta, com acúmulo de 5,93 kg ha ${ }^{-1}$ de $S$ em folhas e $17,47 \mathrm{~kg} \mathrm{ha}^{-1}$ de $\mathrm{S}$ no bulbo.

\section{Referências}

AULAKH, M. S. Crop responses to sulphur nutrition. In: Sulphur in plants, ABROL,Y. P.; AHMAD, A. (eds). Kluwer, Boston, p.341-358, 2003.

CANTERI, M. G. et al. SASM - Agri : Sistema para análise e separação de médias em experimentos agrícolas pelos métodos Scott-Knott, Tukey e Duncan. Revista Brasileira de Agrocomputação, v.1, n.2, p.18-24. 2001.

COMISSÃO DE QUÍMICA E FERTILIDADE DO SOLO - CQFRS/SC. Manual de adubação e calagem para os Estados do Rio Grande do Sul e Santa Catarina. 10.ed. Porto Alegre, Sociedade Brasileira de Ciência do Solo. 394p. 2004.

IBGE - INSTITUTO BRASILEIRO DE GEOGRAFIA E ESTATÍSTICA. Produção Agrícola. Disponível em: https://sidra.ibge.gov.br/Tabela/1612 . Acesso em: 05 abr 2020.

JAGGI, R. C.; AULAKH, M. S.; SHARMA, R. Impacts of elemental $\mathrm{S}$ applied under various temperature and moisture regimes on $\mathrm{pH}$ and available $\mathrm{P}$ in acidic, neutral and alkaline soils. Biol Fertil Soils, v. 41, p. $52-$ 58. 2005. 
KLIKOCKA, H. Znaczenie siarki w biosferze i nawożeniu roślin. Przemysł Chemiczny, v.89, n.7, p.903-908, 2010.

KURTZ, C.; et al.. Sistema de produção de Cebola. Florianópolis: 2013. 106 p. Epagri, sistemas de produção, 46.

KURTZ, C.; ERNANI, P. R. Produtividade de cebola influenciada pela aplicação de micronutrientes. Revista Brasileira de Ciência do Solo, v.34, p.133-142, 2010.

MENDONÇA, A. T. C.; PEIXOTO, N. Efeitos do espaçamento e de níveis de adubação em cultivares de batata-doce. Horticultura Brasileira, v.9, n.2, p.80-82. 1991.

MALAVOLTA, E.; VITTI, G. C.; OLIVEIRA, S. A. Avaliação do estado nutricional de plantas: princípios e aplicações. Piracicaba: Potafós. 1997, 308 .

NASREEN, S. et al. Sulphur effects on growth responses and yield of onion. Asian Journal of Plant Sciences, v.12, n.12, p.897-902, 2003.

NASREEN, S.; HAQ, S. M. I.; HOSSAIN, M. A. Sulphur effects on growth responses and yield of onion. Asian Journal of Plant Sciences, v.2, n.12, p. 897-902, 2003.

PORTO, D. R. Q. et al.. Acúmulo de macronutrientes pela cultivar de cebola "Superex" estabelecida por semeadura direta. Ciência Rural, v.37, n.4, p.949-955, 2007.

RHEINHEIMER, D. S. et al. Resposta de culturas à aplicação de enxofre e a teores de sulfato num solo de textura arenosa sob plantio direto. Ciência Rural, v..35, n.3, p.562-569, 2005.

RESENDE, G. M.; COSTA, N.V. Cultivo da cebola no Nordeste. Embrapa Semi- Árido, 2007.Disponívelem:<https://sistemasdeproducao.cnpti a.embrapa.br/FontesHTML/Cebola/CultivoCebolaNor deste/socioeconomia.htm>. Acesso em: 09. Fev. 2020.

SAS Institute. Base SAS 9.1.3 Procedures Guide SAS Ver. 9.1.3. Cary, SAS Institute Inc., 2006. 398p.

SCHERER, H. W. Sulphur in crop production. European Journal of Agronomy, v.14, n.1, p.81-111, 2001.
TAIZ L; ZEIGER E. Fisiologia Vegetal. Artimed, 3 ed. 2006. 722p.

TEDESCO, M. J. et al. Análise de solo, plantas e outros materiais. Porto Alegre, Universidade Federal do Rio Grande do Sul, 1995. 174p.

THOMAS, M. D.; HENDRICKS, R. H.; HILL, G. R. Sulfur metabolism in alfafa. Soil Science, v.70, p.19-26. 1950.

VITTI, G. C.; MALAVOLTA, E.; FERREIRA, M. E. Respostas de culturas anuais e perenes à aplicação de enxofre. In: BORKERT, C. M.; LANTMANN, A. F. (Ed.). Enxofre e micronutrientes na agricultura brasileira.Londrina:EMBRAPA/CNPSo/IAPAR/SBC S, p. 61-85. 1988. 